\title{
Application of a Cold Spray Based 3D Printing Process in the Production of EDM Electrodes
}

\author{
Štefanija Klarić, Zlatko Botak, Damien J. Hill, Matthew Harbidge, Rebecca Murray
}

\begin{abstract}
Cold spray process principles allow the production of near-net-shape metal parts with a fast layer deposition by using 3D printing techniques via supersonic 3D deposition (SP3D). This innovative additive manufacturing process allows an easy and quick production of copper and aluminium parts with future possibilities to expand materials and alloys. The speed and materials enable the application of this cold spray based 3D printing process for the production of tools. In this paper, Electrical Discharge Machining (EDM) electrodes were fabricated by using SP3D to investigate its application in tool production. Requirements for the materials of electrodes and some existing solutions for the production of EDM electrodes with additive manufacturing methods are described first. The fabrication and experimental results are then presented for 3D printed copper EDM electrodes that were tested by using St 37-2 (DIN 17100) steel as the workpiece.
\end{abstract}

Keywords: additive manufacturing; cold spray; EDM; heat treatment; metal printing

\section{INTRODUCTION}

Electrical Discharge Machining (EDM) is a process based on the thermoelectric phenomenon and controlled erosion of material due to repetitive short duration sparks generated in the gap separating the tool and workpiece submerged in liquid dielectric [1-3].

The EDM process is compiled of several phases that are performed continuously until the desired workpiece geometry is achieved $[2,3]$ :

- ignition phase,

- formation of the plasma channel and vapour bubble,

- discharge phase and

- ejection phase.

A major advantage of this process is the possibility of application where machining with more conventional processes would be difficult: workpiece materials with higher hardness (i.e. heat treated steels), micro machining requirements, machining of composites or batch production of parts $[1,4]$. Regarding the suitability for EDM processing, Amorim and Weingaertner [3] name electrical conductivity as one of the major properties required from the workpiece. The main parameters of EDM are the type of the EDM machine, workpiece and electrode material, electrode shape and rotation, type of dielectric and method of flushing [3, 5].

Electrical input parameters that must be taken into consideration for EDM are $[5,6]$ : discharge current $\left(I_{\mathrm{p}}\right)$, gap voltage $\left(V_{\mathrm{g}}\right)$, pulse ON time $\left(T_{\mathrm{on}}\right)$ and pulse OFF time $\left(T_{\text {off }}\right)$, polarity, electrode gap, pulse frequency and duty factor.

The effectiveness of the process is measured by the material removal rate, electrode wear, wear ration (ratio of the electrode and material removal rate), surface finish and the difference between the electrode and cavity size (over cut) [5-9].

Apart from the above mentioned parameters, Amorim and Weingaertner $[2,3]$ name the workpiece material removal rate, electrode resistance to wear, workpiece surface roughness, tool electrode material machinability and tool electrode material cost as important factors for the electrode material selection.

\subsection{EDM Process and Materials for Electrodes}

The main considerations for the EDM electrode are the erosion of the workpiece and transmission of electric current $[7,8]$. Therefore, in the selection of electrode material, apart from the above mentioned parameters, electrical and thermal conductivity, the melting point, chemical composition and mechanical properties must be taken into consideration [914].

Due to the mentioned requirements, the first obvious choice for an electrode are metallic materials. Typical metals used for EDM electrodes are copper, brass, silver, tungsten, zinc, copper tungsten, silver tungsten, tungsten carbide and tellurium copper $[10,11]$. Another very important material in EDM tool production is Graphite (Graphite has lower density and can hence be used for larger electrodes [3], it has a high melting point, but lower mechanical properties than metallic materials [11]). In order to mitigate the fragility of pure graphite, copper graphite electrodes can be used [11].

According to [3], the use of a different electrode material can produce the same results (Copper vs. Graphite). However, the cost difference must be taken into consideration.

Copper as an electrode material has some advantages over graphite. Copper is used for applications that require a highly polished surface or coined shape (for engraving), and it is a good choice for a wire EDM [3, 9].

In this paper, EDM electrodes from cold sprayed copper powder were produced by using the additive manufacturing technology SP3D.

\subsection{Additive Manufacturing for EDM Electrode Production}

Tool production is often connected to the manufacturing of products with (often) complex geometry, limited number of pieces [15] and requirements for specific material properties (i.e. high wear resistance or conductivity). Additive manufacturing introduces some benefits in tool production, such as the decrease of fabrication time or costs, possible elimination or reduction of manufacturing steps and 
improvement of tool design/functionality $[15,16]$. These benefits allow a valid case to be made to investigate the possibilities of an additive manufacturing application for the production of EDM electrodes.

In the 1990's, attempts were made to apply stereolithography (STL) models for EDM tool production $[17,18]$. Further development of rapid tooling processes resulted in several possible variations of the additive manufacturing of EDM electrodes that could be produced from non-conductive materials (i.e. stereolithography forwarded by metallisation), conductive materials (selective laser sintering (SLS) process) or cast made materials [19-21].

The area of Metal Additive Manufacturing (Metal AM) has been rapidly growing in last five years as it is used for the production of parts in the automotive, aircraft, medical technology industry and in the defence domain [22]. The development of new processes such as SP3D printing (based on the cold spraying of metal) opened the possibility of an investigation of another EDM electrode production method directly from conductive materials (copper).

\section{SPEE3D PRINTING OF COPPER}

The copper electrodes used in this experiment were 3D printed on a LightSPEE3D printer (SPEE3D, Australia). LightSPEE3D printers utilize a patented Supersonic 3D Deposition (SP3D) process to deposit material into near-netshape bulk components. The process is derived from the existing cold spray (CS) technology. CS has been and still is used in repair and coating operations around the world, but is primarily limited to 2-dimensional applications. SPEE3D's technology utilizes its software, TwinSPEE3D, to slice a specified geometry and generate toolpaths by using sophisticated algorithms. The software generates a preprogramed path that a 6 axis robot arm performs over a stationary cold-spray gun to build a part in 3 dimensions.

Unlike the existing 3D printing technologies which require heat to melt material [23-25], SP3D is a kinetic process. Metal particles are accelerated up to Mach 3 [26]. The kinetic energy at this speed causes particles to highly plastically deform when they splat (technical term) onto the surface of the substrate, or part. This creates a high-density metal part as more material is continuously added. Since the SP3D process is not thermal, it is capable of producing parts significantly faster than other technologies by achieving high deposition rates. A limiting factor on thermal based technologies is the time required to melt and then solidify the material before the next layer is laid down.

Currently, LightSPEE3D is capable of printing aluminium, copper, and various copper and aluminium alloys. Research is being conducted to increase the number of materials that can be printed with useful metallurgical properties for numerous applications using the SP3D technology. Examples of material possibilities include bronzes, stainless steel and titanium, which are all able to be cold sprayed with the existing technologies [27].

The LightSPEE3D printer can produce copper parts at up to $100 \mathrm{~g} / \mathrm{min}$ [26]. However, for the purpose of EDM tools, the machine deposited material at $20 \mathrm{~g} / \mathrm{min}$ in order to increase deposition efficiency and dimensional accuracy as a higher production speed was not necessary. The deposition efficiency (DE) at $20 \mathrm{~g} / \mathrm{min}$ is approximately $90 \%$, with $10 \%$ of the powder being removed with a dust extraction system to be recycled.

\section{EXPERIMENTAL SETUP \\ 3.1 EDM Electrode Production}

EDM electrodes (samples $1-9$, Tab. 1, Fig. 1) were produced with the following parameters:

- Printing parameters:

- Carrier gas: air,

- Carrier gas stagnation temperature: $400{ }^{\circ} \mathrm{C}$,

- Carrier gas stagnation pressure: $30 \mathrm{bar}$,

- Substrate: deoxidized 5052 aluminium at room temperature

- Printing layer thickness: $1.68 \mathrm{~mm}$

- Printing time for 4 samples: $90 \mathrm{~min}$

- Powder material: AMPS 99.9\% Copper, D50 $=30 \mu \mathrm{m}$, D10-D90 $=10$ to $45 \mu \mathrm{m}$

- Electrode geometry is shown in Fig. 1

- Post-printing heat treatment parameters are shown in Tab.1. After the treatment, electrodes were machined on a lathe to final dimensions.

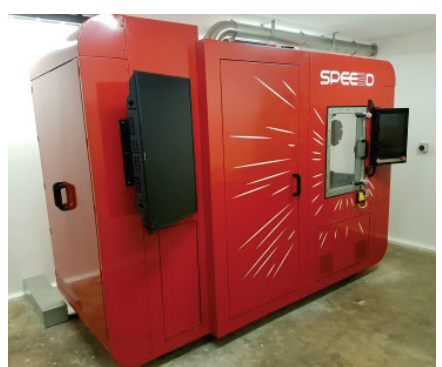

(a)

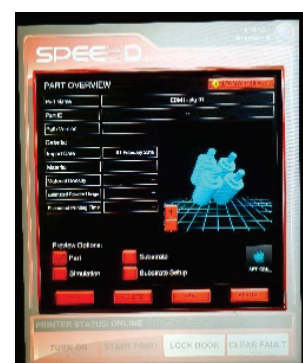

(b)

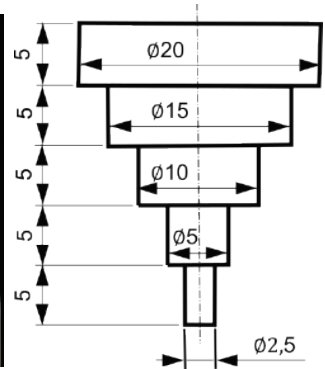

(c)

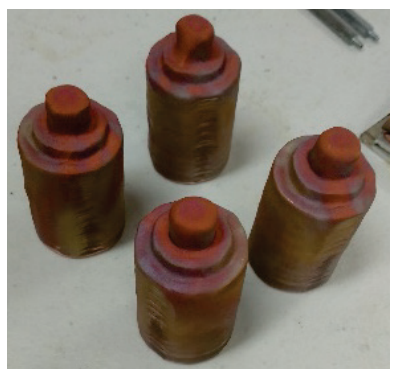

(d)

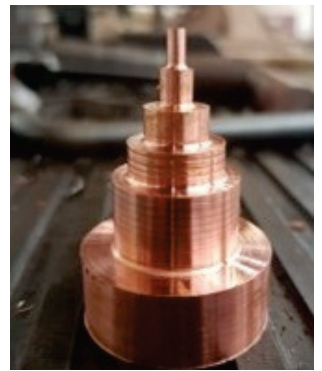

(e)

Figure 1 Electrodes were produced on the LightSPEE3D printer (a) using a pre-set geometry as displayed on the HMI (b), with dimensions given in mm (c). The as-printed samples (e) were then heat-treated according to Tab. 1, then machined on a lathe to produce the SP3D printed electrode (f).

The printed parts underwent different heat treatment regimes: 1) no heat treatment, 2) $330{ }^{\circ} \mathrm{C}, 3$ hours, water quench 3) $400{ }^{\circ} \mathrm{C} 3$ hours, water quench (Tab. 1). A control sample that was produced from the copper bar stock (sample 10, Tab. 1) was included. Heat treatment was performed to reduce the cold working of the material. Oxidation levels and 
conductivity of the 3D printed material are planned to be tested between groups in future research.

Table 1 Post printing heat treatment parameters

\begin{tabular}{|c|c|c|}
\hline Sample no. & $\begin{array}{c}\text { Heat treatment } \\
\text { temperature, }{ }^{\circ} \mathrm{C}\end{array}$ & Heat treatment time / quenching media \\
\hline 1 & 400 & 3 hours / water \\
\hline 2 & 330 & 3 hours / water \\
\hline 3 & \multicolumn{2}{|c|}{ Not treated } \\
\hline 4 & 330 & Not treated \\
\hline 5 & 330 & 3 hours / water \\
\hline 6 & 400 & 3 hours / water \\
\hline 7 & \multicolumn{2}{|c|}{ Produced from copper bar by machining } \\
\hline 8 & \multicolumn{2}{|c}{} \\
\hline 9 & \multicolumn{2}{|c}{} \\
\hline 10 & \multicolumn{2}{|c|}{} \\
\hline
\end{tabular}

Machining the as printed components to the required geometry on a lathe was difficult due to the brittle nature of the cold sprayed parts. The material does not deflect, but instead, areas with small cross sections would break in the lathe. The feed rate and depth of the cut were lowered to compensate. A 4-jaw chuck rather than a 3-jaw chuck was needed to adjust for the larger variation in the as printed geometry compared to a typical bar stock.

\subsection{EDM Machining}

EDM testing was performed on an AG80L Die sinker EDM machine (Sodic Europe Ltd.) in industrial conditions in the Gumiimpex-GRP company in Varaždin, with the following parameters:

- Workpiece: St $37-2$ steel plate $(123 \times 70 \times 30 \mathrm{~mm})$ milled and grinded, without thermal processing. Tab. 2 shows the mechanical properties and Tab. 3 shows the thermo-physical data from the Iordachescu M et al. study (as cited in [28])

- Dielectric: EDMFLUID $108 \mathrm{MP} / \mathrm{S}$.

Table 2 Mechanical properties of the St $37-2$ material (thickness: $16.1<40 \mathrm{~mm}$ )

\begin{tabular}{|c|c|}
\hline [29] \\
\hline Property & Value \\
\hline Tensile strength, MPa & $360-510$ \\
\hline Yield strength, MPa & 225 \\
\hline Elongation, $\%$ & 26 \\
\hline Impact energy $\mathrm{KV} 20^{\circ} \mathrm{C}, \mathrm{J}$ & $>27$ \\
\hline
\end{tabular}

Table 3 Thermo-physical data of the St 37-2 material [28]

\begin{tabular}{|c|c|c|c|c|c|c|c|}
\hline Temperature, ${ }^{\circ} \mathrm{C}$ & 20 & 200 & 400 & 600 & 800 & 1000 & 1600 \\
\hline Specific heat, $\mathrm{J} / \mathrm{kg}{ }^{\circ} \mathrm{C}$ & 465 & 527 & 606 & 761 & 685 & 618 & 840 \\
\hline Density, $\mathrm{kg} / \mathrm{m}^{3}$ & 7850 & 7770 & 7700 & 7630 & 7590 & 7510 & 7100 \\
\hline $\begin{array}{c}\text { Conductivity, } \\
\mathrm{W} / \mathrm{m}{ }^{\circ} \mathrm{C}\end{array}$ & 48.07 & 43.89 & 38.04 & 31.77 & 25.50 & 28.01 & 34.28 \\
\hline
\end{tabular}

Table 4 Chemical composition of the St 37-2 material

\begin{tabular}{|c|c||c|c||c|c|}
\hline Element & $\%$ & Element & $\%$ & Element & $\%$ \\
\hline $\mathrm{Al}$ & 0.0265 & $\mathrm{Mn}$ & 1.2726 & $\mathrm{~S}$ & 0.0108 \\
\hline $\mathrm{C}$ & 0.1511 & $\mathrm{Nb}$ & 0.0325 & $\mathrm{Si}$ & 0.2433 \\
\hline $\mathrm{Co}$ & 0.0318 & $\mathrm{Ni}$ & 0.0468 & $\mathrm{~V}$ & 0.0390 \\
\hline $\mathrm{Cr}$ & 0.0174 & $\mathrm{P}$ & 0.0156 & $\mathrm{Fe}$ & 98.110 \\
\hline & & & & Other & 0.0026 \\
\hline
\end{tabular}

The chemical composition of the St 37-2 material was measured by using the optical emission spectrometer ARL
3460, which has a database for steel, copper and aluminium. The spectrometer analysis results are shown in Tab. 4.

The used EDM parameters are shown in Tab. 5.

\begin{tabular}{|c|c|c|c|}
\multicolumn{1}{c}{ Table 5 EDM parameters } \\
\begin{tabular}{|c|c|c|c|}
\hline Tool electrode & Copper & Workpiece material & St 37-2 steel \\
\hline Polarity & + & Peak Current, A & 5 \\
\hline Pulse on time, $\mu \mathrm{s}$ & 110 & Voltage, $\mathrm{V}$ & 55 \\
\hline Pulse off time, $\mu \mathrm{s}$ & 45 & Dielectric fluid & $\begin{array}{c}\text { EDMFLUID } \\
108 \mathrm{MP} / \mathrm{S}\end{array}$ \\
\hline Surface Roughness, $\mu \mathrm{m}$ & $4,1-4,4$ & Overcut, $\mu \mathrm{m} /$ Side & 80 \\
\hline
\end{tabular}
\end{tabular}

Based on the expected roughness of the treated surface, the machine automatically selected the processing parameters, such as the metal removal rate, pulse ON time, pulse OFF time and electricity power.

\section{RESULTS}

The obtained test results of the application of the cold spray based printing method, SP3D, for the production of EDM electrodes have shown that material is usable and comparable with the traditionally produced copper electrodes. The test results for all electrodes described in Tab. 1 are shown in Figs. 2-6. Note that no distinct differences are seen at a macro level of the control (sample 10) from the 3D printed samples (Figs. 2-6).

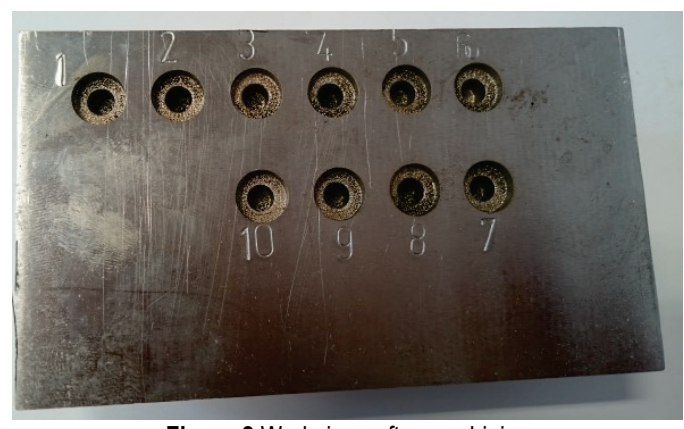

Figure 2 Workpiece after machining
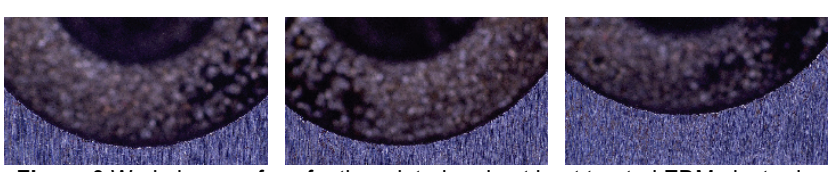

Figure 3 Workpiece surface for the printed and not heat treated EDM electrode (samples 3, 5, 8)

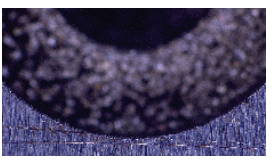

Figure 4 Workpiece surface for the printed and $330^{\circ} \mathrm{C}$ heat treated EDM electrode (samples 2, 4,6)
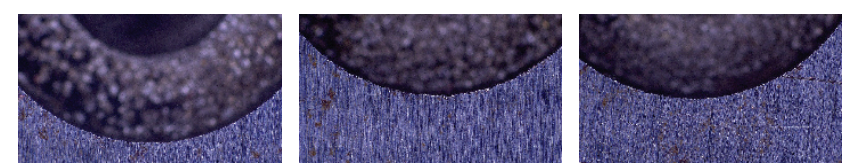

Figure 5 Workpiece surface for the printed and $400{ }^{\circ} \mathrm{C}$ heat treated EDM electrode (samples 1,7,9) 
The St 37-2 workpiece surface condition after machining with printed electrodes that were not heat treated after printing is shown in Fig. 3. Fig. 4 shows the workpiece surfaces machined with electrodes that were heat treated to $330^{\circ} \mathrm{C}$, and the surfaces machined with electrodes that were heated to $400{ }^{\circ} \mathrm{C}$ are shown in Fig. 5 .

The surface produced by an electrode that was made by a solid copper bar is shown in Fig. 6 .

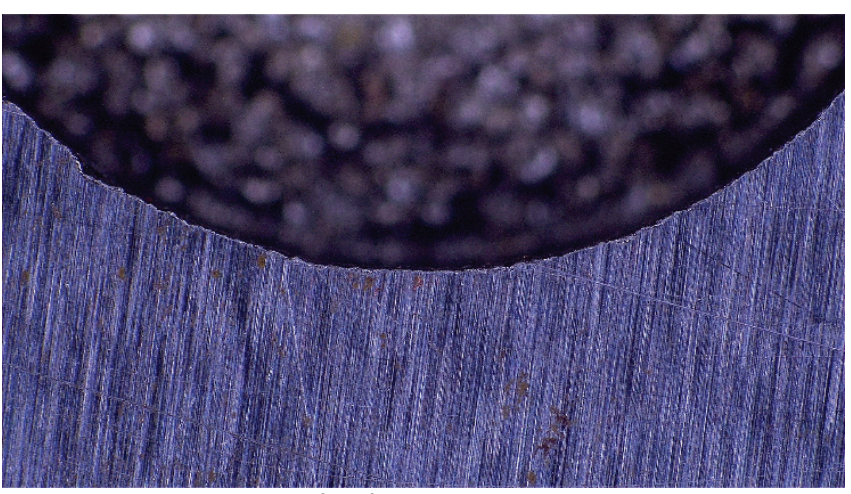

Figure 6 Workpiece surface for a bar stock produced EDM electrode (control, sample 10)

The presented results show a possible application of the SP3D printing of metals for the production of EDM electrodes. As this process is cheap and fast in comparison to other metal printing processes [26], it could provide a unique solution in situations where a specific shape of the tool is required.

Research in EDM has produced investigations of processes with electrode cooling in order to reduce electrode wearing $[30,31]$. This fact combined with the fact that the SP3D technology can produce solid objects with enclosed channels leads to the possibility that the SP3D printing technology could be a solution for the production of electrodes (and tools in general) with built-in liquid cooling systems.

\section{CONCLUSION}

The development of a new additive manufacturing process based on cold spray opened a range of possibilities in tool production. In this preliminary research, the SP3D technology was tested for the production of copper EDM electrodes. Three different groups of printed EDM electrodes that varied by heat treatment were compared with a conventionally produced copper electrode (Tab. 1). All electrodes were tested on a mild steel workpiece. Preliminary results have shown that a cold spray based 3D printing technology can be used for EDM with a satisfactory production output.

In the future, research will be conducted in order to increase the efficiency of electrode production and application regarding the following: the influence of heat treatment temperature on conductivity, SP3D produced electrode wear rates and possibly, introduction of the alloying of copper powder in order to improve mechanical properties of electrode materials.

\section{REFERENCES}

[1] Ranganath, B. J. (2008). Thermal Metal Cutting Processes. New Delhi, India: I. K. International Publishing House Pvt. Ltd

[2] Amorim, F. L. \& Weingaertner, W. L. (2004). Die-Sinking Electrical Discharge Machining of a High-Strength CopperBased Alloy for Injection Molds. J. of the Braz. Soc. of Mech. Sci. \& Eng., XXVI(2), 138-144. https://doi.org/10.1590/S1678-58782004000200004

[3] Amorim, F. L. \& Weingaertner, W.L. (2007). The Behavior of Graphite and Copper Electrodes on the Finish Die-Sinking Electrical Discharge Machining (EDM) of AISI P20 Tool Steel. J. of the Braz. Soc. of Mech. Sci. \& Eng., XXIX(4), 366371. https://doi.org/10.1590/S1678-58782007000400004

[4] Shabgard, M. R., Gholipoor, A., \& Baseri, H. (2016). A review on recent developments in machining methods based on electrical discharge phenomena. Int J Adv Manuf Technol, 87, 2081-2097. https://doi.org/10.1007/s00170-016-8554-z

[5] Jeevamalar, J. \& Ramabalan, S. (2015). Die sinking EDM process parameters: a review. Int. J. Mech. Eng. \& Rob. Res., 4 (1), 315-326.

[6] Dave, H., Banker, M., Kumar, S., Mathai, V. J., \& Vyas, A. (2016). Investigation on the effect of different tool-workpiece combinations on MRR and TWR during EDM process. Journal of Machining and Forming Technologies, 7 (3-4), 171-181.

[7] Sultan, T., Kumar, A., \& Gupta, R. D. (2014). Material Removal Rate, Electrode Wear Rate, and Surface Roughness Evaluation in Die Sinking EDM with Hollow Tool through Response Surface Methodology. International Journal of Manufacturing Engineering, 2014. https://doi.org/10.1155/2014/259129

[8] Singh, G., Singh, G., Singh. K., \& Singla. A. (2017). Experimental studies on material removal rate, tool wear rate and surface properties of machined surface by powder mixed electric discharge machining. Materials Today: Proceedings 4, 1065-1073.

[9] Ahmad, S. \& Lajis, M. A. (2013). Electrical discharge machining (EDM) of Inconel 718 by using copper electrode at higher peak current and pulse duration. IOP Conference Series: Materials Science and Engineering, 50 (1), 012062 , https://doi.org/ 10.1088/1757-899X/50/1/012062

[10] Sommer, C. (2001, August). EDM electrodes - a matter of choosing wisely different materials affect machining. Tooling \& Production, 53-56.

[11] Kern, R. (2008, July/August). Sinker electrode material selection. EDM Today, Retrieved from http://www.edmtodaymagazine.com/2015/archives/techtips/2 008 may_jun_tech_tip/\#p=3

[12] Daneshmand, S., Neyestanak, A. A. L., \& Monfared, V. (2016). Modelling and investigating the effect of input parameters on surface roughness in electrical discharge machining of CK45. Tehnicki Vjesnik - Technical Gazette, 23(3), 725-730. https://doi.org/10.17559/tv-20141024224809

[13] Ghose, J., Sharma, V., Kumar, N., Krishnamurthy, A., Kumar, S., \& Botak, Z. (2011). Taguchi-fuzzy based mapping of EDMmachinability of aluminium foam. Tehnicki Vjesnik - Technical Gazette, 18(4), 595-600.

[14] Bhuyan, R. K., Routara, B. C., \& Parida, A. K. (2015). Using entropy weight, OEC and fuzzy logic for optimizing the parameters during EDM of Al-24\% SiC. Advances in Production Engineering \& Management, 10(4), 217-227. https://doi.org/10.14743/apem2015.4.204

[15] Cotteleer, M., Neier, M., \& Crane, J. (2014, April 07). 3D opportunity in tooling: Additive manufacturing shapes the future. Retrieved from https://www2.deloitte.com 
/insights/us/en/focus/3d-opportunity/additive-manufacturing3d-opportunity-in-tooling.html

[16] Leal, R., Barreiros, F. M., Alves, L., Romeiro, F., Vasco, J. C., \& Santos, M. (2017). Additive manufacturing tooling for the automotive industry. Int J Adv Manuf Technol, 92, 1671-1678. https://doi.org/10.1007/s00170-017-0239-8

[17] Ferreira, J. C., Mateus, A. S., \& Aves, A. F. (2006). Rapid tooling aided by reverse engineering to manufacture EDM electrodes. Int J Adv Manuf Technol., 34(11), 1133-1143. https://doi.org/ 10.1007/s00170-006-0690-4

[18] Stucker, B., Bradley, W. L., Norasetthekul, S., \& Eubank, P. T. (1995, August). The Production of Electrical Discharge Machining Electrodes Using SLS: Preliminary Results. Paper presented at the Sixth Solid Freeform Fabrication (SFF) Symposium, Austin, Texas, USA. Retrieved from http://sffsymposium.engr.utexas.edu/Manuscripts/1995/199533-Stucker.pdf

[19] Kechagias, J., Iakovakis, V., Katsanos, M., \& Maropoulos, A. (2008). EDM electrode manufacture using rapid tooling: a review. J Mater Sci, 43(8), 2522-2535. https://doi.org/10.1007/s10853-008-2453-0

[20] Ablyaz, T. R., Shumkov, A. A., \& Muratov, K. R. (2017). Studying the Technology of Creating Cortical Electrode Instruments using the Rapid Prototyping Technology. Archives of Foundry Engineering, 14(2), 157-162. https://doi.org/ 10.1515/afe-2017-0068

[21] Amorim, F. L., Lohrengel, A., Müller, N., Schäfer, G., Müller, N., \& Czelusniak, T. (2013). Performance of sinking EDM electrodes made by selective laser sintering technique. Int $J$ Adv Manuf Technol., 65, 1423-1428. https://doi.org/10.1007/s00170-012-4267-0

[22] Goldense, B. L. (2018, June 21). Metal AM: Metal Additive Manufacturing Hits Critical Mass. Machine Design. Retrieved from https://www.machinedesign.com/3d-printing/metal-ammetal-additive-manufacturing-hits-critical-mass-pdfdownload

[23] Knezovic, N. \& Dolsak, B. (2018). In-process non-destructive ultrasonic testing application during wire plus arc additive manufacturing. Advances in Production Engineering \& Management, 13(2), 158-168. https://doi.org/10.14743/apem2018.2.281

[24] Bellacicca, A., Santaniello, T., \& Milani, P. (2018). Embedding electronics in $3 \mathrm{D}$ printed structures by combining fused filament fabrication and supersonic cluster beam deposition. Additive Manufacturing, 24, 60-66. https://doi.org/10.1016/j.addma.2018.09.010

[25] Ameen, W., Al-Ahmari, A., Mohammed, M. K., Abdulhameed, O., Umer, U., \& Moiduddin, K. (2018). Design, finite element analysis (FEA), and fabrication of custom titanium alloy cranial implant using electron beam melting additive manufacturing. Advances in Production Engineering \& Management, 13 (3), 267-278. https://doi.org/10.14743/apem2018.3.289

[26] Goehrke, S. (2018, May 16). SPEE3D is here to Compete with Casting, 3D Printing Metal at Thrice the Speed of Sound. Retrieved from https://www.spee3d.com/2018/05/16/spee3dcompete-casting-3d-printing-metal-thrice-speed-sound-sarahgoehrke/

[27] Rokni, M. R., Nutt, S. R., Widener, C. A., Champagne, V. K., \& Hrabe, R. H. (2017). Review of Relationship Between Particle Deformation, Coating Microstructure, and Properties in High-Pressure Cold Spray. J Therm Spray Tech, 26, 13081355. https://doi.org/ 10.1007/s11666-017-0575-0
[28] Kumar, P. \& Sinha, A. N. (2018). Studies of temperature distribution for laser welding of dissimilar thin sheets through finite element method. J Braz. Soc. Mech. Sci. Eng. 40, 455. https://doi.org/ 10.1007/s40430-018-1380-5

[29] HRN EN 10025-2:2007: Toplo valjani proizvodi od konstrukcijskih čelika -- 2. dio: Tehnički uvjeti isporuke za nelegirane konstrukcijske čelike (EN 10025-2:2004); Hot rolled products of structural steels - Part 2: Technical delivery conditions for non-alloy structural steels EN 10025-2:2004. (2004). Hrvatski zavod za norme, Zagreb.

[30] Abdulkareem, S., Khan, A. A., \& Konneh, M. (2010). Cooling Effect on Electrode and Process Parameters in EDM. Materials and Manufacturing Processes, 25, 462-466. https://doi.org/ 10.1080/15394450902996619

[31] Hui, Z.; Liu, Z.; Cao, Z., \& Qiu, M. (2016) Effect of Cryogenic Cooling of Tool Electrode on Machining Titanium Alloy (Ti6Al-4V) during EDM, Materials and Manufacturing Processes, 31 (4), 475-482.

https://doi.org/10.1080/10426914.2015.1037893

\section{Authors' contacts:}

Štefanija Klarić, PhD

College of Engineering, IT and Environment, Charles Darwin University,

Ellengowan Dr, Casuarina 0810, NT, Australia

061889466416, stefanija.klaric@cdu.edu.au

Zlatko Botak, $\mathrm{PhD}$

University North,

Department of Mechanical Engineering,

104. brigade 1, HR-42000 Varaždin, Croatia

042493 339, zlatko.botak@unin.hr

Damien J. Hill, BEng MRes

College of Engineering, IT and Environment, Charles Darwin University,

Ellengowan Dr, Casuarina 0810, NT, Australia damien.hill@cdu.edu.au

\section{Matthew Harbidge, BEng \\ Advanced Manufacturing Alliance, \\ Charles Darwin University, \\ Ellengowan Dr, Casuarina 0810, NT, Australia \\ matthew.harbidge@cdu.edu.au}

Rebecca Murray, Dr.-Ing., MSc. Advanced Manufacturing Alliance, Charles Darwin University,

Ellengowan Dr, Casuarina 0810, NT, Australia rebecca.murray@cdu.edu.au 